\title{
Solid serous adenoma of the pancreas: a rare form of serous cystadenoma
}

\author{
Madhusudhan R. Sanaka \\ Thomas Jefferson University \\ Thomas E. Kowalski \\ Thomas Jefferson University \\ Corey Brotz \\ Thomas Jefferson University \\ Charles J. Yeo \\ Thomas Jefferson University \\ Peter McCue \\ Thomas Jefferson University \\ Follow this and additional works at: https://jdc.jefferson.edu/medfp \\ Part of the Medical Genetics Commons

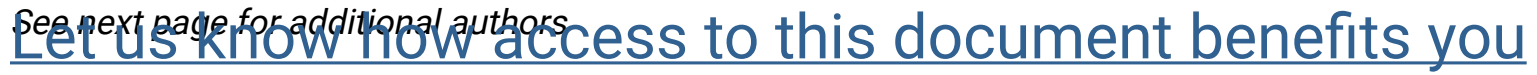

\section{Recommended Citation}

Sanaka, Madhusudhan R.; Kowalski, Thomas E.; Brotz, Corey; Yeo, Charles J.; McCue, Peter; and Palazzo, Juan, "Solid serous adenoma of the pancreas: a rare form of serous cystadenoma" (2008). Department of Medicine Faculty Papers. Paper 29.

https://jdc.jefferson.edu/medfp/29

This Article is brought to you for free and open access by the Jefferson Digital Commons. The Jefferson Digital Commons is a service of Thomas Jefferson University's Center for Teaching and Learning (CTL). The Commons is a showcase for Jefferson books and journals, peer-reviewed scholarly publications, unique historical collections from the University archives, and teaching tools. The Jefferson Digital Commons allows researchers and interested readers anywhere in the world to learn about and keep up to date with Jefferson scholarship. This article has been accepted for inclusion in Department of Medicine Faculty Papers by an authorized administrator of the Jefferson Digital Commons. For more information, please contact: JeffersonDigitalCommons@jefferson.edu. 
Authors

Madhusudhan R. Sanaka, Thomas E. Kowalski, Corey Brotz, Charles J. Yeo, Peter McCue, and Juan

Palazzo

This article is available at Jefferson Digital Commons: https://jdc.jefferson.edu/medfp/29 


\title{
Solid serous adenoma of the pancreas, a rare form of serous cystadenoma
}

\author{
Madhusudhan R. Sanaka, Thomas E. Kowalski, Corey Brotz, Charles J. Yeo,
} Peter McCue and Juan Palazzo

\section{Introduction:}

Serous cystadenomas (SC) of the pancreas are uncommon benign cystic neoplasms that were first differentiated from mucinous cystadenomas in 1978 by Compagno and Oertel (1-3). Serous cystadenomas characteristically have a spongy gross appearance and are composed of innumerable tiny cysts lined by flattened cuboidal or polygonal cells with clear to pale eosinophilic cytoplasm atop of thin fibrous septae.

Since 1978, five unique SC subtypes have been identified (4-5). Here we report a case of a solid serous adenoma, a rare serous cystadenoma subtype.

\section{Case report:}

A 74 year-old man was incidentally found to have a pancreatic mass during an evaluation for renal colic. An abdominal CT scan revealed a $1.5 \mathrm{~cm}$ diameter, enhancing mass in the anterior aspect of the body of the pancreas (Figure 1). An endoscopic ultrasound demonstrated a $1.9 \times 1.3 \mathrm{~cm}$ well circumscribed, hypoechoic mass (Figure 2). The pancreatic parenchyma appeared normal as did the adjacent vascular structures. There was no peripancreatic or celiac axis lympadenopathy. Fine needle aspiration of the mass was performed, but the specimen was found to be inadequate for cytologic evaluation. Concern for malignancy prompted surgical consultation and plan for surgical resection. Intraoperatively, the mass was found to be encapsulated and was enucleated. 
Due to the proximity of the resection cavity to the main pancreatic duct, the cavity was drained via a Roux-en-Y pancreaticojejunostomy. Gross pathology demonstrated a $1.6 \mathrm{x}$ $1.3 \mathrm{~cm}$ well-demarcated solid mass (Figure 3). Microscopic study showed an encapsulated tumor composed of vague nodules with dense collagenous septa (Figure 4). The tumor cells had small round nuclei and clear or pale amorphophilic cytoplasm (Figure 5). There was no necrosis, cytologic atypia, or abnormal mitotic figures. Some tumor cells contained glycogen granules as demonstrated by periodic acid-Schiff (PAS) staining. Immunohistochemical staining revealed tumor cells positive for cytokeratin CAM 5.2 and negative for synaptophysin and chromogranin. The tumor was diagnosed as a solid serous adenoma of the pancreas. The patient recovered uneventfully and was discharged home on postoperative day 5 . The patient was seen two month postoperatively and was fully recovered.

\section{Discussion:}

Solid serous adenoma of the pancreas is an extremely rare benign tumor of the pancreas. The tumor was first described in 1996 (1) as a solid pancreatic tumor composed of cells morphologically and histochemically indistinguishable from those of SC, and was therefore thought to represent a solid SC variant. The second report published in 2004, confirmed the existence of a solid pancreatic tumor with cells morphologically and immunohistochemically indistinguishable from those of SC and distinct from other known solid tumors of the pancreas, supporting solid serous adenoma as a SC subtype (2).

It is postulated that the cells of solid serous adenoma are SC cells that lack secretory capability and it is the secretion of serous fluid that imparts the cystic architecture to serous cystadenomas (1). 
Solid serous adenomas are therefore well-circumscribed tumors formed by clear to pale polygonal to cuboidal cells arranged in nests, sheets, and trabeculae separated by thick fibrous bands. Although small acini with glandular spaces may be present, cystic spaces are absent. PAS and PAS-diastase stains show abundant cytoplasmic glycogen. Histologically, the differential diagnosis includes the rare primary clear-cell "sugar" tumor of the pancreas, clear cell carcinoma, clear cell islet cell tumor, and metastatic renal cell carcinoma (1). These other rare solid tumors of the pancreas are excluded on immunohistochemical bases. As such, solid serous adenomas are immunoreactive for CAM 5.2, epithelial membrane antigen, and neuron-specific enolase but negative for HMB-45, synaptophysin, chromogranin, insulin, glucagon pancreatic peptide, gastrin, somatostatin, vasoactive intestinal polypeptide, serotonin, bombesin, calcitonin, lipase 21, lipase 105, chymotrypsin, and trypsin.

Similar to other pancreatic incidentalomas, solid serous adenomas are usually asymptomatic and incidental findings on imaging studies performed for other reasons (6). The rarity of these tumors, the difficulty in achieving a definitive preoperative diagnosis, and the potential for malignancy invariably leads to the recommendation for surgical excision. Accordingly, our patient underwent surgery with enucleation of a wellencapsulated tumor and no evidence of residual or metastatic disease. He is asymptomatic after six months. In two of the previously reported cases, patients were well at 1 and 5 years post-operatively (1-2). Similarly, we expect our patient to continue to do well. In conclusion, solid serous adenoma is an extremely rare, benign pancreatic tumor with solid architecture but cytologic, histochemical, and immunohistochemical features identical to that of serous cystadenoma. 


\section{References:}

1. Perez-Ordonez B, Naseem A, Lieberman PH, Klimstra DS. Solid serous adenoma of the pancreas. The solid variant of serous cystadenoma? Am J Surg Pathol. 1996 Nov; 20(11): 1401-5.

2. Yamaguchi M. Solid serous adenoma of the pancreas: a solid variant of serous cystadenoma or a separate disease entity? J Gastroenterol. 2006 Feb; 41(2): 178-9.

3. Compagno J, Oertel JE. Microcystic adenomas of the pancreas (glycogen-rich cystadenomas): a clinicopathologic study of 34 cases. Am J Clin Pathol. 1978; 69: 289298.

4. Kosmahl M, Wagner J, Peters K, Sipos B, Kloppel G. Serous cystic neoplasms of the pancreas: an immunohistochemical analysis revealing alpha-inhibin, neuron-specific enolase, and MUC6 as new markers. Am J Surg Pathol. 2004 Mar; 28(3): 339-46. 5. Brugge WR, Lauwers GY, Sahani D, Fernandez-del Castillo C, Warshaw AL. Cystic neoplasms of the pancreas. N Engl J Med. 2004 Sep 16; 351(12): 1218-26. Review. 6. Winter JM, Cameron JL, Lillemoe KD, Campbell KA, Chang D, Riall TS, Coleman J, Sauter PK, Canto M, Hruban RH, Schulick RD, Choti MA, Yeo CJ. Periampullary and Pancreatic Incidentaloma: A single institution's experience with an increasingly common diagnosis. Ann Surg. 2006 May; 243 (5): 673-683. 
Figures \& Legends

\section{Figure 1}

Abdominal CT scan showing 1.5-cm hypervascular arrow) in the anterior aspect of the body of the pancreas

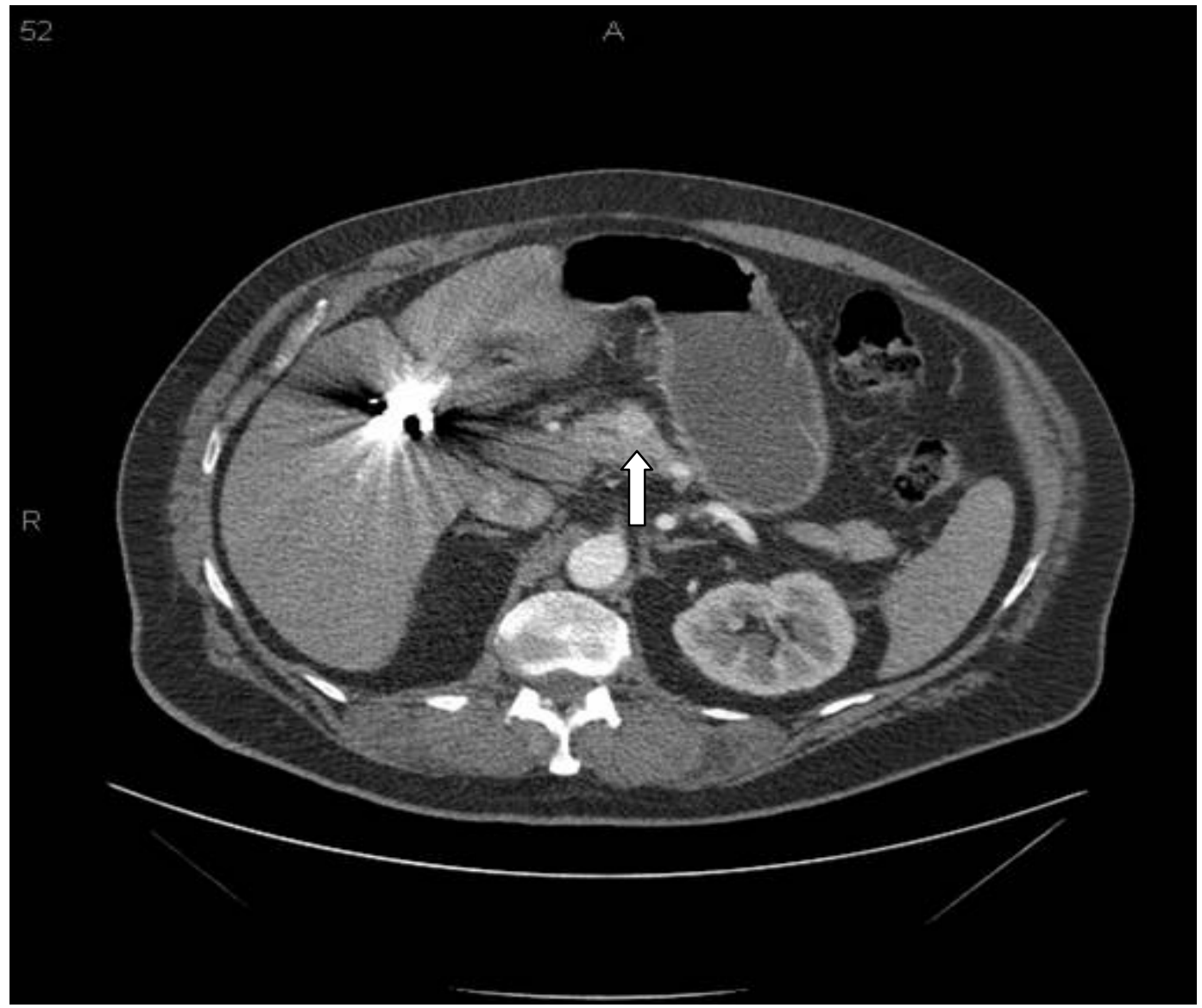




\section{Figure 2}

Endoscopic ultrasound showing 1.9-× 1.3-cm hypoechoic mass (arrow) in the body of the pancreas

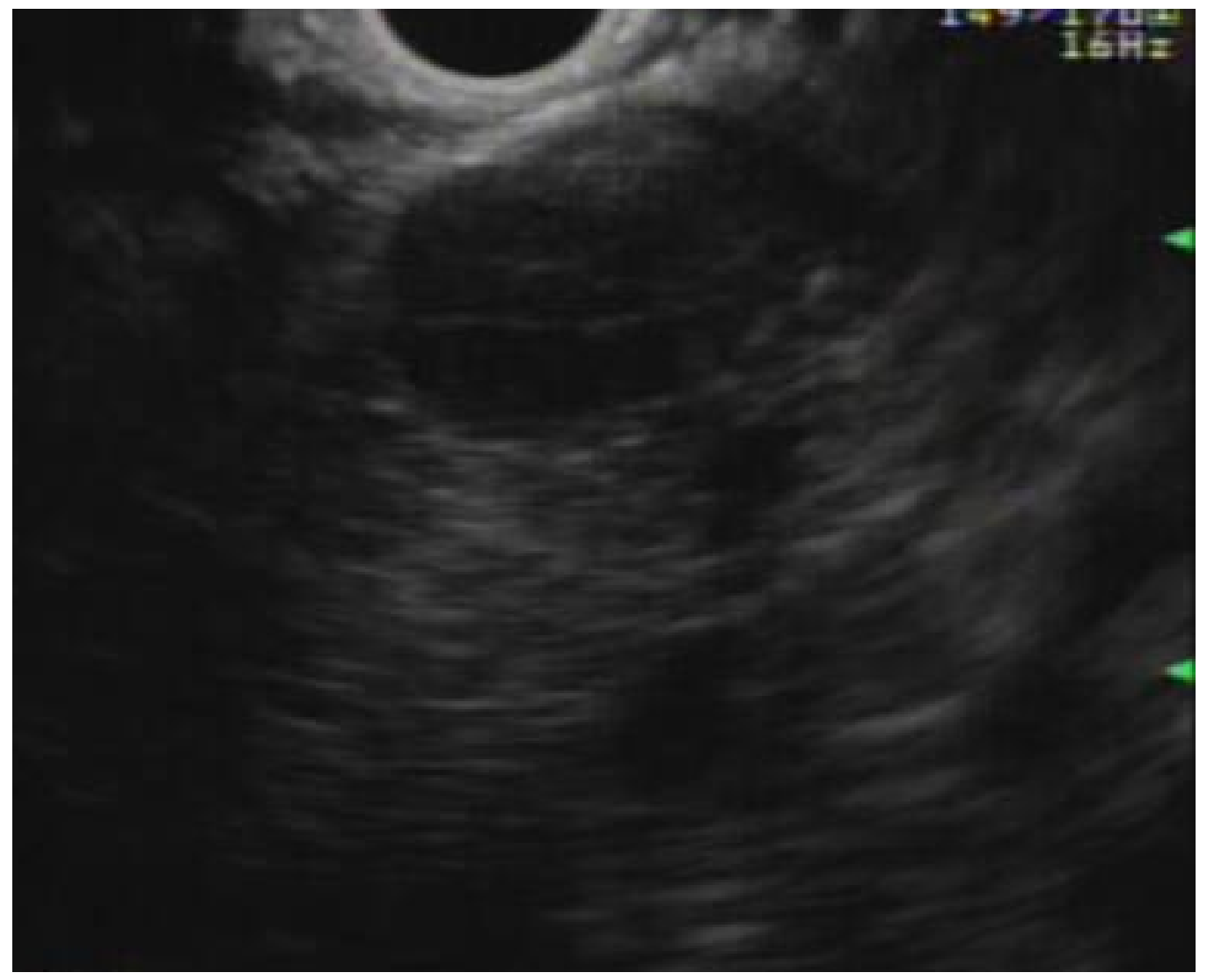


Figure 3

Gross surgical specimen demonstrating a well-demarcated solid mass. 
Figure 4

Low-power microscopy revealing an encapsulated tumor composed of nodules and dense collagenous septa (hematoxylin and eosin; original magnification, $\times 10$ )

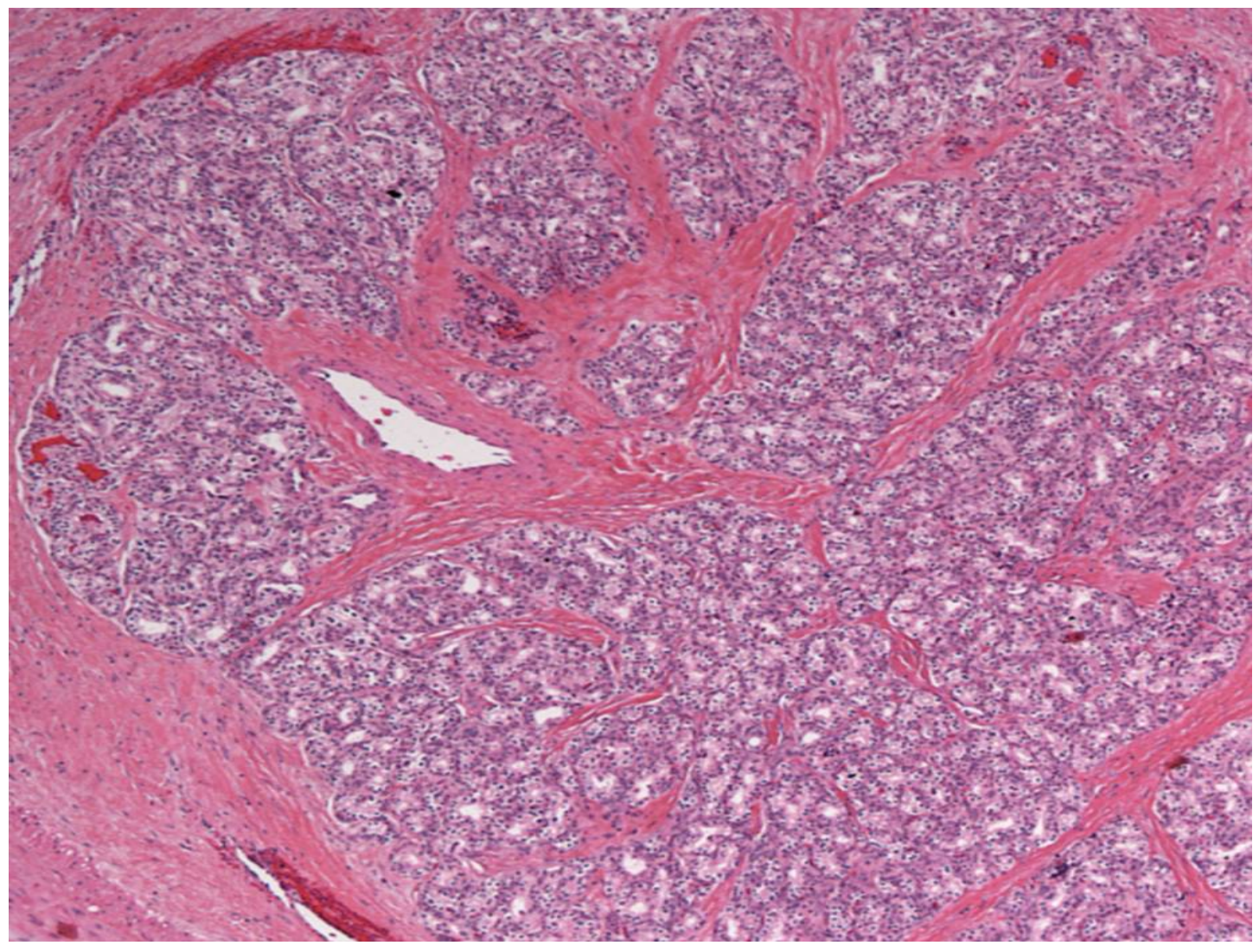




\section{Figure 5}

High-power microscopy showing bland appearing cuboidal cells with small round nuclei and pale eosinophilic cytoplasm (hematoxylin and eosin; original magnification, $\times 40$ )

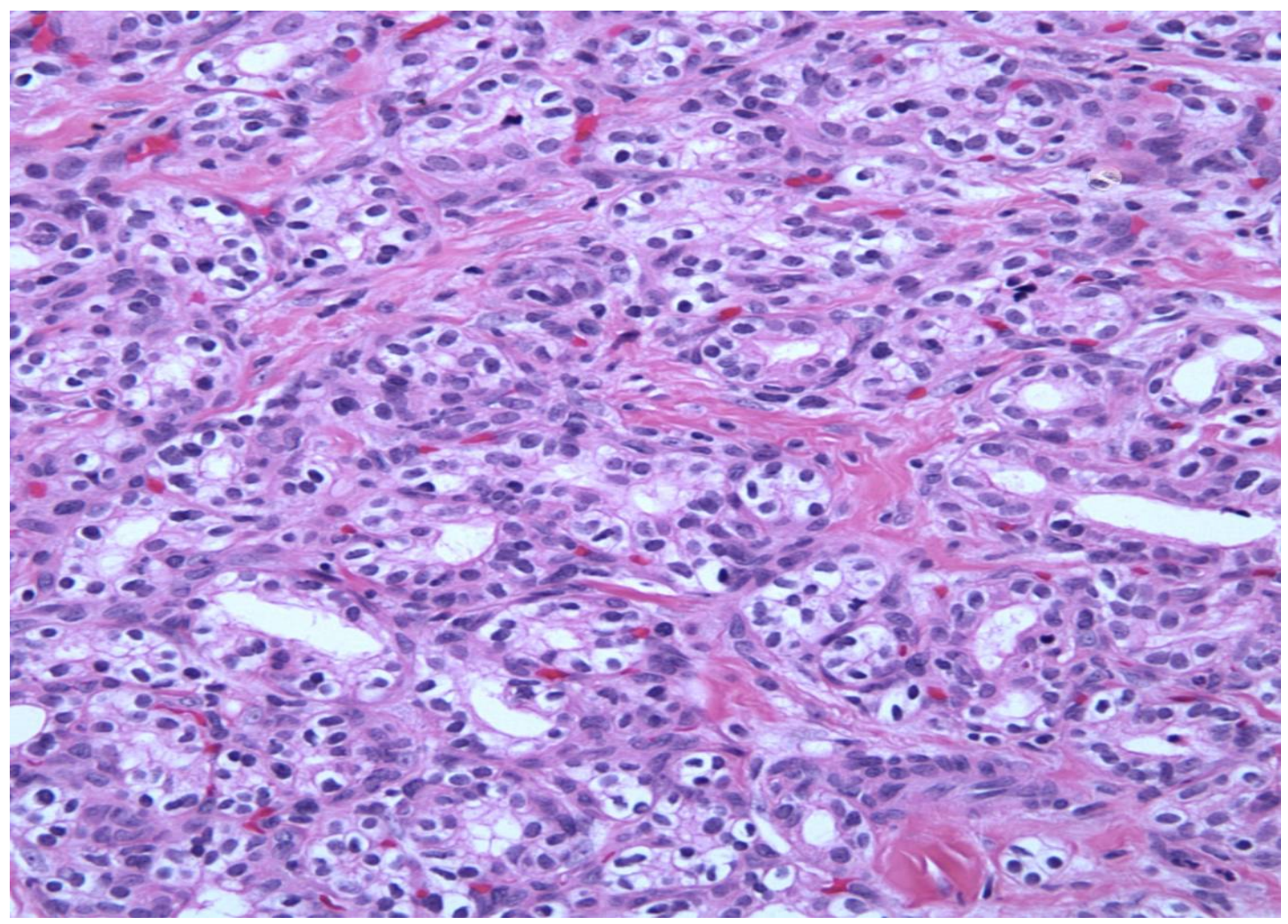


